\title{
Implementasi Metode Weighted Product Menentukan Beasiswa Bidik Misi Stmik Pringsewu
}

\author{
Muhamad Muslihudin $^{1}$, Trisnawati ${ }^{2}$, Renita Fitri Andriyanti ${ }^{3}$, Siti Mukodimah $^{4}$ \\ ${ }^{1,2,3,4}$ Prodi Sistem Informasi, STMIK Pringsewu Lampung \\ muslihudinstmikpsw@gmail.com ${ }^{1}$,renitafitri4@gmail.com ${ }^{3}$
}

\begin{abstract}
As the contents of the Law article 76 no.12 Year 2012 on Higher education, STMIK Pringsewu is one of the universities that provide scholarships to outstanding students or underprivileged students such as Bidik Misi scholarship. Shutter Mission is an educational tuition aid for prospective new students are not economically capable but have good academic potential. The goal is to ease the burden of student education expenses. In determining whether or not a student is awarded a scholarship, it is necessary to build a Decision Support System in order to produce more accurate decisions using the Weighted Product method. Researchers use the Weighted Product method because this method is very easy in making decisions. From each student will be judged based on predetermined criteria, then done the ranking process to get the final value then produce the greatest value so will determine the selected alternatives in the research. Based on the test results, the built system can, speed up the selection process and also can reduce the occurrence of errors. This system is built with PHP Programming Language using MySql database. Based on the five students who have been determined then the final result is really worthy of receiving Bidik Misi scholarship is alternative 1 with the largest Vi vector value 0.240202
\end{abstract}

Keywords: Bidik Misi, Weighted Product, Scholarship, PHP

\begin{abstract}
Abstrak
Sebagai isi UU pasal 76 no.12 Tahun 2012 tentang Pendidikan Tinggi, STMIK Pringsewu merupakan salah satu universitas yang memberikan beasiswa kepada siswa berprestasi atau mahasiswa kurang mampu seperti beasiswa Bidik Misi. Shutter Mission adalah bantuan dana pendidikan bagi calon siswa baru yang tidak mampu secara ekonomi namun memiliki potensi akademis yang baik. Tujuannya adalah untuk meringankan beban biaya pendidikan siswa. Dalam menentukan apakah seorang siswa diberi beasiswa atau tidak, perlu membuat Sistem Pendukung Keputusan untuk menghasilkan keputusan yang lebih akurat dengan menggunakan metode Weighted Product. Periset menggunakan metode Weighted Product karena metode ini sangat mudah dalam mengambil keputusan. Dari masing-masing siswa akan dinilai berdasarkan kriteria yang telah ditentukan, kemudian dilakukan proses pemeringkatan untuk mendapatkan nilai akhir kemudian menghasilkan nilai terbesar sehingga akan menentukan alternatif yang dipilih dalam penelitian. Berdasarkan hasil pengujian, sistem yang dibangun bisa, mempercepat proses seleksi dan juga dapat mengurangi terjadinya kesalahan. Sistem ini dibangun dengan PHP Programming Language menggunakan database MySql. Berdasarkan kelima siswa yang telah ditentukan maka hasil akhirnya yang benar-benar layak menerima beasiswa Bidik Misi adalah alternatif 1 dengan nilai vektor Vi terbesar 0,240202
\end{abstract}

Kata kunci: Bidik Misi, Produk Tertimbang, Beasiswa, PHP 


\section{PENDAHULUAN}

Idik misi adalah bantuan biaya pendidikan, berbeda dari beasiswa yang berfokus pada $\mathrm{B}$ memberikan penghargaan atau dukungan dana terhadap mereka yang berprestasi, bidik misi berfokus kepada yang memiliki keterbatasan kemampuan ekonomi. (Bidik Misi Kemenristekdikti, 2014). Bidik

misi adalah program bantuan biaya pendidikan yang diberikan Pemerintah melalui Direktorat Jenderal Pendidikan Tinggi (Ditjen Dikti) Kementerian Pendidikan dan Kebudayaan mulai tahun 2010 kepada mahasiswa yang memiliki potensi akademik memadai dan kurang mampu secara ekonomi.Pemberian berupa bantuan keuangan yang diberikan kepada perorangan yang bertujuan untuk digunakan demi keberlangsungan pendidikan yang ditempuh. Beasiswa diberikan secara selektif sesuai dengan jenis beasiswa bidik misi. Salah satunya adalah beasiswa mahasiswa berprestasi dan beasiswa mahasiswa kurang mampu[1][2].

Beberapa penelitian terdahulu seperti yang dilakukan oleh Rika Wahyuni (2016), Sistem Pendukung Keputusan Penentuan Penerimaan Beasiswa Bidik Misi dengan menggunakan Weighted Product dapat di rancang untuk mempermudah dalam menentukan siapa yang berhak mendapatkan beasiswa bidikmisi. Sistem pendukung Keputusan yang dirancang ini dapat mempercepat proses penyeleksian beasiswa, karena proses seleksi dilakukan secara otomatis. Dimana tim penyeleksi menginput data-data pada form bagian input dengan benar dan sesuai dengan ketentuan yang ada selanjutnya data mahasiswa tersebut akan langsung masuk dalam tahap penyeleksian dengan metode Weighted Product sehingga mendapatkan hasil penerima beasiswa dari hasil proses sistem tersebut[3].

Penelitian yang dilakukan oleh Eko Adi Nugroho dan Setia Astuti (2015), dengan adanya sistem yang dibuat ini dapat membantu dengan cepat proses penyeleksian mahasiswa dan juga menghasilkan keputusan yang lebih objektif berupa daftar mahasiswa yang layak menerima beasiswa bidik misi. Sistem pendukung keputusan ini dibuat hanya sebagai alat ukur untuk memberikan informasi kepada Universitas Dian Nuswantoro Semarang sebagai referensi pertimbangan dalam pengambilan keputusan[4].

Sebagai sarana untuk mengetahui Mahasiswa mana yang berhak menerima beasiswa Bidik Misi tersebut atau siapa yang terpilih untuk menerima beasiswa sesuai dengan syarat-syarat yang ditentukan oleh dikti, maka di terapkanlah metode Weighted Product ini. Metode Weighted Product ialah metode penyelesaian dari beberapa atribut, dimana setiap atribut harus dipangkatkan terlebih dahulu dengan bobot atribut yang sebelumnya sudah ditentukan. Selain itu STMIK Pringsewu juga dapat menentukan sendiri bobot kepentingan dari masing-masing kriteria. Pilihan alternative yang ada dapat memberikan referensi pada pembuat keputusan sebelum mengambil keputusan akhir. Dengan diterapkannya metode ini akan memudahkan STMIK Pringsewu dalam memberikan beasiswa kepada mahasiswa dengan sistem yang sudah terkomputerisasi.

Sistem Pendukung Keputusan dalam menentukan Beasiswa Bidik Misi di STMIK Pringsewu akan dapat membantu Dalam menentukan Mahasiswa yang layak. menerima beasiswa bidik misi. Penerapan metode Weighted Product ini lebih efisien karena waktu yang dibutuhkan dalam perhitungan lebih singkat.

\section{METODE PENELITIAN}

\subsection{Metode Pengumpulan Data}

Metode pengumpulan data berdasarkan jenis datanya, data yang dikumpulkan dalam penelitian ini adalah:

1. Studi Pustaka merupakan metode pengumpulan data melalui buku, majalah, modul, e-book, jurnal dan literatur lain yang masih berkaitan dengan pembahasan dan menunjang dalam 
2. penyelesaian laporan penelitian yang tengah dikerjakan. Penulis menggunakan metode Studi Pustaka agar pengumpulan data menjadi lebih lengkap dan untuk mengetahui lebih lanjut apa itu bidik misi.

3. Wawancara informasi merupakan salah satu metode dalam pengumpulan data untuk dapat memperoleh data $\&$ informasi dari narasumber secara lisan. Proses wawancara dilakukan dengan cara tatap muka secara langsung dengan narasumbernya. Penulis menggunakan metode Wawancara untuk mengetahui persyaratan apa saja yang dapat diajukan untuk menerima beasiswa bidik misi.

4. Observasi dapat diartikan suatu pengamatan dan pencatatan secara sistematik terhadap gejala yang tampak pada objek penelitian. Observasi ini lebih banyak digunakan pada statistika survei. Penulis menggunakan metode observasi untuk melihat siapa saja mahasiswa yang berminat untuk mengajukan beasiswa bidik misi tersebut.

\subsection{Weighted Product}

Metode Weighted Product memerlukan proses normalisasi karena metode ini mengalikan hasil penilaian setiap atribut[5][6][7]. Pada dasarnya metode Weighted Product merupakan bagian dari konsep Fuzzy Multiple Attribute Decision Making yang merupakan suatu metode yang digunakan untuk mencari alternatif optimal dari sejumlah alternatif dengan criteria tertentu[8][9][10][11][12]. Metode Weighted Product menggunakan perkalian untuk menghubungkan rating atribut, dimana setiap rating atribut harus dipangkatkan terlebih dahulu dengan bobot yang bersangkutan[13][14]. Metode weighted product dapat membantu dalam mengambil keputusan akan tetapi perhitungan dengan menggunakan metode weighted product ini hanya menghasilkan nilai terbesar yang akan terpilih sebagai alternatif yang terbaik. Perhitungan akan sesuai dengan metode ini apabila alternatif yang terpilih memenuhi kriteria yang telah ditentukan[15]. Preferensi untuk alternatif Ai diberikan sebagai berikut:

$S_{i}=\prod_{j=1}^{n} x_{i j}{ }^{w_{j}}$

Dengan $\mathrm{i}=1,2 \ldots, \mathrm{m}$; dimana $\Sigma \mathrm{Wj}=1$.

$\mathrm{Wj}$ adalah pangkat bernilai positif untuk atribut keuntungan dan bernilai negative untuk atribut biaya[16].

$\mathrm{W}_{\mathrm{j}}=\frac{\mathrm{W}_{\mathrm{j}}}{\sum \mathrm{W}_{\mathrm{j}}}$

Preferensi relatif dari setiap alternatif, diberikan sebagai berikut :

$$
V_{i}=\frac{\prod_{j=1}^{n} x_{i j}{ }^{w_{j}}}{\prod_{j=1}^{n}\left(X_{j}\right)^{w_{j}}} ; \mathrm{i}=1,2, . ., \mathrm{m}
$$

\section{HASIL DAN PEMBAHASAN}

\subsection{Pembahasan Perhitungan Manual}

Berdasarkan langkah-langkah pemecahan masalah dengan menggunakan metode WP yang telah dijelaskan sebelumnya, pada bagian ini akan membahas tentang proses hasil perhitungan dan keluaran penentuan mahasiswa yang berhak menerima beasiswa bidik misi. Adapun skor atau nilai yang digunakan disini yaitu berdasarkan kriteria yang ada: 
Tabel 1. Kreteria dan Nilai Bobot

\begin{tabular}{|c|l|c|}
\hline Kriteria & \multicolumn{1}{|c|}{ Ket. Kriteria } & Bobot (\%) \\
\hline C1 & Indeks Prestasi Semester & 25 \\
\hline C2 & Penghasilan Orang Tua & 20 \\
\hline C3 & Jumlah Tanggungan & 15 \\
\hline C4 & Pengabdian PKM & 25 \\
\hline C5 & Kelayakan Rumah & 15 \\
\hline
\end{tabular}

\subsection{Menentukan Rating Kecocokan}

Berdasarkan rating diatas dapat dibentuk matriks keputusan X, yaitu:

Tabel 2. Rating Kecocokan Alternatif

\begin{tabular}{|c|c|c|c|c|c|}
\hline \multirow[b]{2}{*}{ Alternatif } & \multicolumn{5}{|c|}{ Kriteria } \\
\hline & $\bar{U}$ & $\mathcal{U}$ & $\mathcal{U}$ & U & 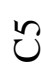 \\
\hline $\mathrm{A} 1$ & 5 & 1 & 4 & 5 & 2 \\
\hline A2 & 3 & 4 & 2 & 1 & 5 \\
\hline A3 & 4 & 1 & 3 & 5 & 1 \\
\hline $\mathrm{A} 4$ & 2 & 3 & 4 & 1 & 3 \\
\hline A5 & 1 & 5 & 2 & 3 & 5 \\
\hline
\end{tabular}

\subsection{Menentukan Normalisasi Bobot}

$\mathrm{W}=(25,20,15,25,15)$

Maka perbaikan bobot yang dilakukan:

$\mathrm{W} 1=\frac{25}{25+20+15+25+15}=0,25$

$\mathrm{W} 2=\frac{20}{25+20+15+25+15}=0,2$

$\mathrm{W} 3=\frac{15}{25+20+15+25+15}=0,15$

$\mathrm{W} 4=\frac{25}{25+20+15+25+15}=0,25$

$\mathrm{W} 5=\frac{15}{25+20+15+25+15}=0,15$

Jika nilai $\mathrm{W} 1+\mathrm{W} 2+\mathrm{W} 3+\mathrm{W} 4+\mathrm{W} 5$ hasilnya adalah $=1$

\subsection{Menentukan Nilai Vektor $S$}

Menentukan nilai vektor $S$ dengan mengalikan seluruh kriteria bagi sebuah alternatif dengan bobot sebagai pangkat positif (+) dan pangkat negatif (-).

$S 1=\left(5^{0,25}\right)\left(1^{0,2}\right)\left(4^{0,15}\right)\left(5^{0,25}\right)\left(2^{0,15}\right)=3,054559$

$S 2=\left(3^{0,25}\right)\left(4^{0,2}\right)\left(2^{0,15}\right)\left(1^{0,25}\right)\left(5^{0,15}\right)=2,45297$ 


$$
\begin{aligned}
& S 3=\left(4^{0,25}\right)\left(1^{0,2}\right)\left(3^{0,15}\right)\left(5^{0,25}\right)\left(1^{0,15}\right)=2,43594 \\
& S 4=\left(2^{0,25}\right)\left(3^{0,2}\right)\left(4^{0,15}\right)\left(1^{0,25}\right)\left(3^{0,15}\right)=2,150597 \\
& S 5=\left(1^{0,25}\right)\left(5^{0,2}\right)\left(2^{0,15}\right)\left(3^{0,25}\right)\left(5^{0,15}\right)=2,564923
\end{aligned}
$$

\subsubsection{Menentukan Nilai Vektor V}

$$
\begin{aligned}
& \mathrm{V} 1=\frac{3,054559}{3,054559+2,45297+2,493594+2,150597+2,564923}=0,240202 \\
& \mathrm{~V} 2=\frac{2,45297}{3,054559+2,45297+2,493594+2,1505997+2,564923}=0,192895 \\
& \mathrm{~V} 3=\frac{2,493594}{3,0545599+2,45297+2,493594+2,150597+2,564923}=0,196089 \\
& \mathrm{~V} 4=\frac{2,150597}{3,0545599+2,45297+2,493594+2,150597+2,564923}=0,169117 \\
& \mathrm{~V} 5=\frac{2,564923}{3,054559+2,45297+2,493594+2,1505997+2,564923}=0,201698
\end{aligned}
$$

Kriteria terbesar adalah Alternatif 1 (V1) karena memiliki IPK tertinggi dan ia berasal dari keluarga yang tidak mampu.

\subsection{Pembahasan Perhitungan Menggunakan Aplikasi SPK}

Setelah mencari hasil manual menggunakan Ms. Excel, peneliti mencoba mencari hasil dengan aplikasi perhitungan yang sudah dirancang dengan PHP MySQL. Adapun hasilnya adalah seperti gambar-gambar dibawah ini. Berikut adalah tampilan Login. (User: admin, Password: admin)

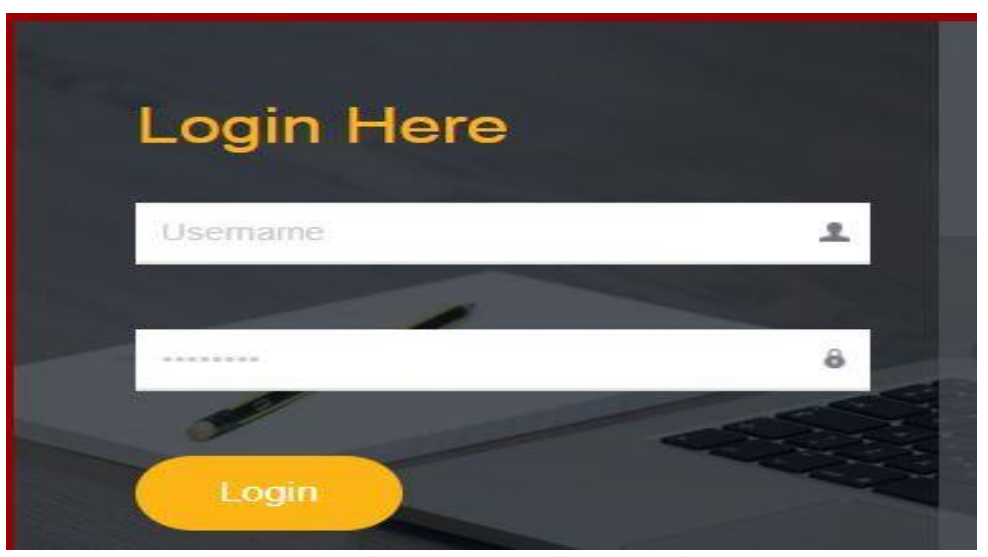

Gambar 1. Tampilan Login

Setelah login, masuk ke halaman menentukan Kriteria. 


\begin{tabular}{|c|c|c|c|c|c|}
\hline$\square$ & Nama Kriteria & $0 \|$ & Keterangan Nilai & $\|$ & Jumlah Nilai \\
\hline$\square$ & Indeks Prestasi Semester & 0 & $\mathrm{Cl}$ & & 25 \\
\hline$\square$ & Penghasilan Orang Tua & 0 & C2 & & 20 \\
\hline$\square$ & Jumlah Tanggungan & 0 & c3 & & 15 \\
\hline$\square$ & Pengabdian PKM & 0 & c4 & & 25 \\
\hline$\square$ & Kelayakan Rumah & 0 & $c 5$ & & 15 \\
\hline$\square$ & Nama Kriteria & 0 & Keterangan Nilai & & Jumlah Nilai \\
\hline
\end{tabular}

Gambar 2. Menginput Kriteria dan Nilai

Setelah menginput kriteria, terlebih dahulu harus menginputkan bobot dan nilai bobot yang sudah dikalikan.

\begin{tabular}{|c|c|c|c|c|c|c|c|}
\hline 0 & Kinteria & If Niliaboot & If Hasil Bobot & $\square \mathfrak{l}$ & Nama Alternatif & Vektor S & Vektor V \\
\hline 0 & Indeles Prestas Semester & 25 & 0.25 & 0 & Renita & 3.0545588741038467 & 0.24020168086121 \\
\hline 0 & Penghassian Orang Tue & 20 & 0.2 & 0 & Bobby & 2.452970424513578 & 0.19289450403665 \\
\hline U & Jumbar langungan & 15 & 0.15 & Q & Fitri & & \\
\hline 0 & Pengabodian PXM & 25 & 0.25 & & & & \\
\hline 0 & Kelaraken Rumanh & 15. & N & & & & 0.16911669341994 \\
\hline 0 & Kinteria & Nili Bobot & Hasil Bobot & & & 2.5649228972079654 & 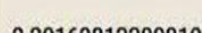 \\
\hline
\end{tabular}

Gambar 3. Bobot dari Setiap Kriteria dan Nilai Vektor S dan Vektor V 


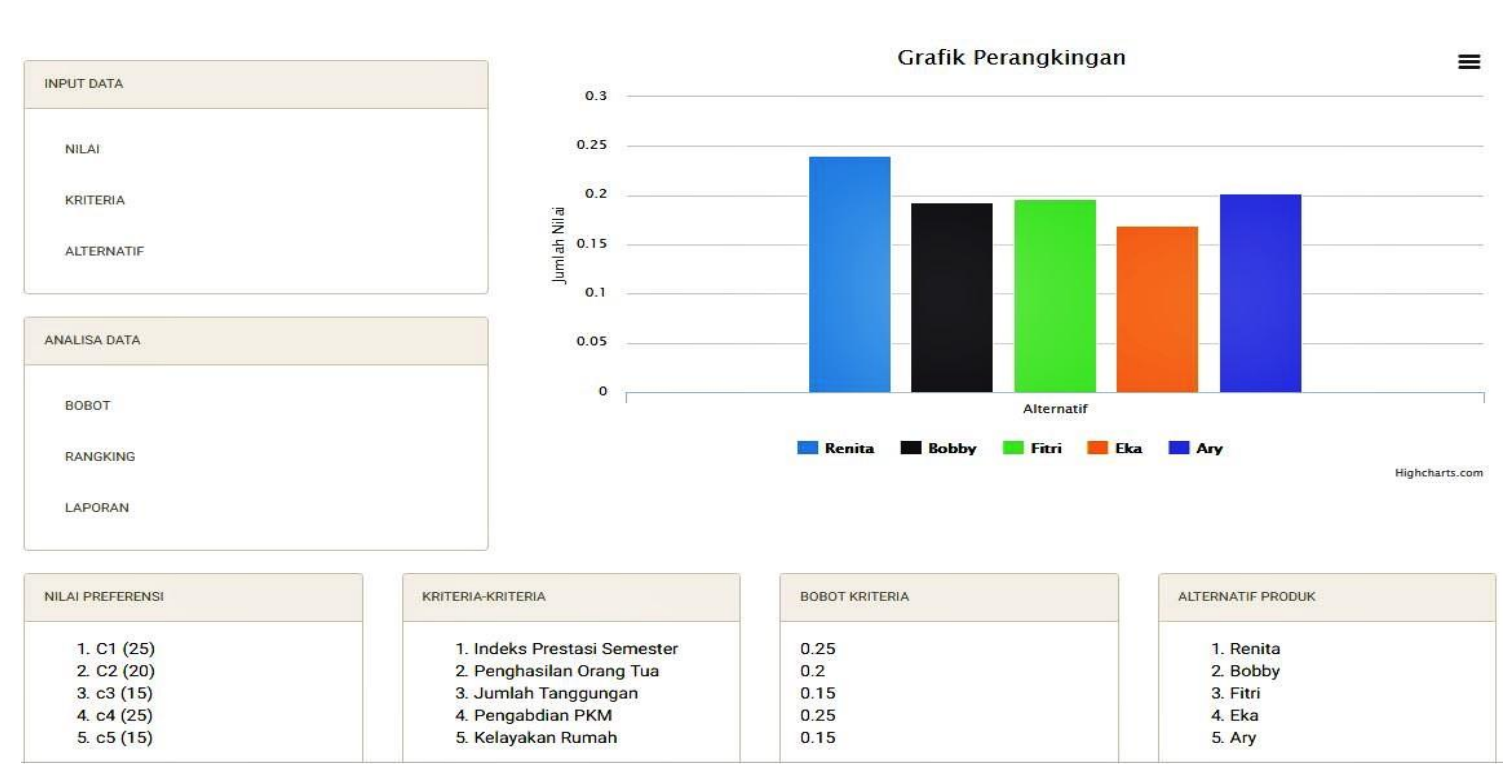

Gambar 4. Bobot dari Setiap di Tampilkan dalam Bentuk Grafik

\section{KESIMPULAN DAN SARAN}

\subsection{Kesimpulan}

Sistem Pendukung Keputusan untuk menentukan penerimaan beasiswa Bidik Misi pada STMIK Pringsewu dapat membantu dan mempermudah Perguruan Tinggi dalam menentukan mahasiswa yang layak atau tidaknya mendapatkan beasiswa berdasarkan kriteria-kriteria yang telah ditentukan. Dari hasil nilai yang diperoleh maka Alternatif 1 memperolah nilai terbesar yaitu dengan IPK tertinggi dan termasuk dalam kategori Mahasiswa dari keluarga tidak mampu.

\subsection{Saran}

Berdasarkan kesimpulan diatas diharapkan agar Sistem Informasi ini dapat dikembangkan lebih jauh dengan pengolahan data calon mahasiswa penerima Bidik Misi yang baru. Semoga sistem ini dapat digunakan sebagai salah satu pengambilan keputusan Penerimaan Beasiswa Bidik Misi pada STMIK Pringsewu.

\section{DAFTAR PUSTAKA}

[1] K, Dikti. 2014, Pedoman Penyelenggaraan Bantuan Biaya Pendidikan Bidikmisi Tahun 2014.

[2] A. D. W, KIisworo. 2017, "Model Sistem Pendukung Keputusan Menggunakan Metode Fmadm untuk Seleksi Beasiswa A-PPA Dan Bbp-Ppa Pada Perguruan Tinggi," pp. 1-6.

[3] W. Rika Wahyuni. 2016, "Sistem Pendukung Keputusan Penerimaan Beasiswa Bidik Misi di Universitas Almuslim dengan Menggunakan Metode Weighted Product," J. Univ. Almuslim, Vol. 1, No. 2, pp. 64-71.

[4] E. A. Nugroho and S. Astuti. 2015, "Implementasi Algoritma Weighted Product untuk Mendukung Keputusan Penerimaan Beasiswa Bidikmisi pada Universitas Dian Nuswantoro Semarang," J. UNDINUS, Vol. 1, No. 1, pp. 1-5. 
[5] S. Kusumadewi, S. Hartati, A. Harjoko, and Retanto Wardoyo. 2013, Fuzzy MultiAttribute Decision Making (Fuzzy MADM). Graha Ilmu, Yogyakarta.

[6] S. A. K. Sukadari, Suyata. 2015, "Penelitian Etnografi Tentang Budaya Sekolah Dalam Pendidikan Karakter Di Sekolah Dasar.” pp. 1-11.

[7] Yoga Handoko Agustin and H. Kurniawan. 2015, "Sistem Pendukung Keputusan Penilaian Kinerja Dosen Menggunakan Metode Weighted Product (Studi Kasus : Stmik Pontianak)," Semin. Nas. Inform. 2015, pp. 177-182.

[8] M. Muslihudin, T. S. Susanti, A. Maseleno, and S. Pringsewu. 2018, "The Priority of Rural Road Development using Fuzzy Logic Based Simple Additive Weighting," Int. J. Pure Appl. Math., Vol. 118, No. 8, pp. 9-16.

[9] S. Mukodimah, M. Muslihudin, A. Andoyo, S. Hartati, and A. Maseleno. 2018, "Fuzzy Simple Additive Weighting and its Application to Toddler Healthy Food," Int. J. Pure Appl. Math., Vol. 118, No. 7, pp. 1-7.

[10] M. Muslihudin, F. Triananingsih, and L. Anggraei. 2017, "Pembuatan Model Penilaian Indeks Kinerja Dosen Menggunakan Metode Fuzzy Simple Additive Weighting," SEMNASTEKNOMEDIA, Vol. 5, No. 1, pp. 25-30.

[11] A. Andoyo, M. Muslihudin, and N. Y. Sari. 2017, "Pembuatan Model Penilaian Indeks Kinerja Dosen Menggunakan Metode Fuzzy Multi Attribute Decision Making (FMADM) (Studi : PTS di Provinsi Lampung)," in Prosiding Seminar Nasional Darmajaya, pp. 195-205.

[12] M. Muslihudin and M. Amrullah. 2016, "Model Dss untuk Mengetahui Tingkat Bahaya Asap Kendaraan Menggunakan Metode Fuzzy Multiple Attribute Decision Making (FMADM)," J. TAM ( Technol. Accept. Model ), Vol. 6, No. 1, pp. 9-14.

[13] D. M. Khairina, D. Ivando, and S. Maharani. 2016, "Implementasi Metode Weighted Product untuk Aplikasi Pemilihan Smartphone Android," J. Infote, Vol. 8, No. 1, pp. 18.

[14] A. D. Susanti, M. Muslihudin, and S. Hartati. 2017, "Sistem Pendukung Keputusan Perankingan Calon Siswa Baru Jalur Undangan Menggunakan Simple Additive Weighting (Studi Kasus : SMK Bumi Nusantara Wonosobo)," SEMNASTEKNOMEDIA, vol. 5 , no. 1 , pp. $37-42$.

[15] T. E. Erkan and B. D. Rouyendegh. 2014, "Curriculum Change Parameters Determined by Multi Criteria Decision Making (MCDM)," Procedia - Soc. Behav. Sci., Vol. 116, No. 1987, pp. 1744-1747.

[16] J. R. S. C. Mateo. 2012, "Weighted Sum Method and Weighted Product Method," in Green Energy and Technology, Vol. 83, pp. 19-22. 